\title{
Development trends in practical training of college students in the context of digital transformation of education
}

\author{
Liudmila Nazarova $^{1}{ }^{*}$, Petr Kubrushko ${ }^{1}$, Aleksei Alipichev ${ }^{1}$ and Svetlana Gryazneva ${ }^{2}$ \\ ${ }^{1}$ Russian State Agrarian University - Moscow Timiryazev Agricultural Academy, 127550, Moscow, \\ Russia \\ ${ }^{2}$ Politechnic College No. 8 named after the Twice Hero of the Soviet Union I. F. Pavlov, 125284, \\ Moscow, Russia
}

\begin{abstract}
The study proves the key role of practical training as a basic constituent of the content of secondary vocational education, represented by both apical and implicit components. The study's goal is to identify and highlight the development trends of practical training of college students in the new digital society. The study was carried out on the basis of the Polytechnic College No. 8 and the Russian State Agrarian University Moscow Timiryazev Agricultural Academy. Basic methods involved the analysis of scientific and pedagogical literature, regulatory documents, SWOT analysis, generalization, observation, pedagogical experiment. The authors make a strong case for improving the practice-oriented component of vocational education in the context of it digital transformation. For this purpose, network interaction is actively implemented as a prototype of the dual education system. Analyzing the case of a polytechnic college, the authors show the advantages of using computer models in the process of practical preparation, including the SinuTrain program, which can fully simulate the operation of numerically controlled metal-working machines on a personal computer. In the context of the digital transformation of education, an important trend is the use of VR/AR technologies in the training process. The paper outlines the effectiveness of cooperation between the college and partner enterprises in preparing students for the demonstration exam. The authors prove the necessity of transforming practical training in colleges into a system of dual education on the basis of network interaction. This can be implemented in the form of study and production clusters.
\end{abstract}

\section{Introduction}

The vocational education system in Russia has to be reformed to meet the current challenges and train professionals suitable for the new socio-economic conditions. Year 2020 will always be associated with the pandemic due to the spread of COVID-19, which caused crises

\footnotetext{
*Corresponding author: inboxnazarova@gmail.com
} 
in all spheres of society, including in the system of vocational education, which was forced to switch to the online format as required by social distancing protocols $[1,2]$.

In the secondary vocational education curricula, the leading role belongs to practical training as the basis for the development of the activity-based component of professional competence $[3,4]$. In the context of online learning, the quality of practical training of students has suffered the most. But even in the conditions of the full-time study process, there still remain a lot of problems to be solved, which relate to the organization of practical training. If you do not pay special attention to the selection and coordination of practiceoriented programs and teaching methods, college graduates have an insufficient level of professional knowledge, abilities, skills, and competencies $[5,6]$. Therefore, highly relevant are studies aimed at finding effective training technologies and ways to optimize them in accordance with the requirements of scientific and technological progress, the level of development of modern technologies, including the digital ones [7-10].

Thus, there is a need to develop theoretical and empirical issues to improve the quality of practical training of mid-level specialists for an innovative digital economy who can quickly adapt to production conditions and effectively carry out professional activities.

The goal of this study is to identify and highlight the development trends of practical training of college students in the new digital society, in general, and in education, in particular.

\section{Materials and Methods}

The study was carried out on the basis of the Polytechnic College No. 8 named after the Twice Hero of the Soviet Union I.F. Pavlov and the Department of Pedagogy and Psychology of Professional Education of Russian State Agrarian University - Moscow Timiryazev Agricultural Academy.

The study is methodologically based on systemic, competence-based, personalityoriented and synergistic approaches.

Basic methods involved the analysis of scientific and pedagogical literature on the problems of organizing practical training, the analysis of regulatory documents on practical training and network interaction of colleges and partner enterprises, SWOT analysis implementation of practical training using network technologies as exemplified by a polytechnic college, generalization, observation, pedagogical experiment.

\section{Results}

When hiring young specialists, employers face serious problems - yesterday's students lack practical professional experience, as well as demonstrate a low level of professional adaptability. In hiring new staff, it is impossible to objectively assess the professionalism of a young specialist by the completeness of the study program he has mastered. The use of a competency-based approach in education may help to solve this problem [11]. There have been adopted occupational standards, which formulate the requirements for the results of graduates' education as future employers see them, and, based on the requirements of professional standards, Federal state educational standards are developed. However, the problem of adequate diagnostics of the development of professional competences of graduates still remains relevant.

Competence reflects the ability of a professional to apply knowledge, skills, and personal traits to perform successfully in a particular area $[12,13]$. To acquire professionalism, students should repeat professional actions in a given sequence, and only after mastering this reproductive and re-creating activity a specialist will be able to solve non-standard 
professional tasks [14]. Naturally, this path of personal professionalization is rather complicated and takes a lot of time. That is why it is important that students begin to develop professionalism while still taking courses offered by the educational institution. To do this, it is necessary to improve teaching methods that will allow them to acquire skills in practical work in their specialty even in the years of study. The study process itself should aim at mastering the knowledge and skills, as well as the types of behavior and attitudes that they will need when performing their professional duties in peal work environment in the future.

Training should focus on the learning outcomes that will be important and relevant for the future professional activity. Practical training corresponds to these requirements as this is a form of organizing training activities within a course syllabus while performing certain types of tasks related to future professional activities. These tasks should facilitate the formation, consolidation, and development of practical skills and competences according to the corresponding course syllabus.

In epistemology, practice is considered both as a source of knowledge, and as its driving force, a goal, and a criterion of truth, since it is through practice that the correctness of knowledge is verified. In this regard, it is advisable to consider practical training not just as one of the basic components of the content of training, but as a key basic constituent. According to the law of double entry of the basic components of the training content into the training system (according to V.S. Lednev) [15], the training content should be revealed in an apical (explicitly expressed) and in an implicit (latent, not evident) form. The apical component of practical training is represented primarily by industrial practices and practical exercises, while the implicit component runs through all types of study activities (see Fig. 1).

IMPLICIT COMPONENT

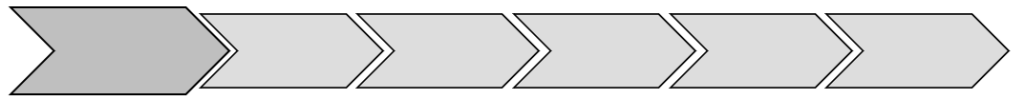

All types of study activities

APICAL COMPONENT

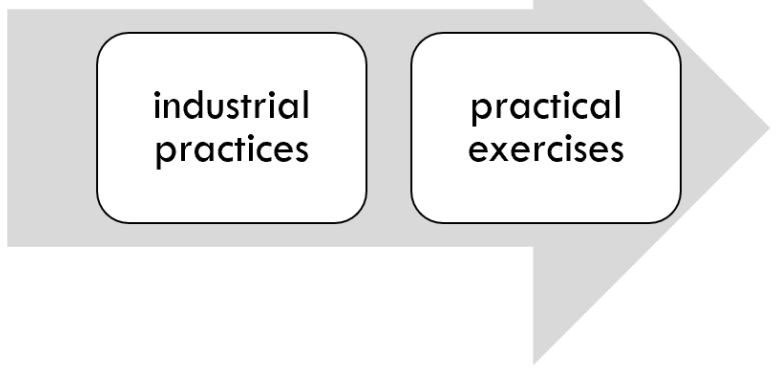

Fig. 1. Components of practical training.

For organizing practical training, the network form of the curricula implementation is being increasingly used, i.e. practical training can be carried out either directly in the educational organization or in the profile organization. The integration of these two forms of practical training is called dual training [16]. This is the most effective practice-oriented system that allows students to get involved in professional activities in an optimal way (see Fig. 2). 


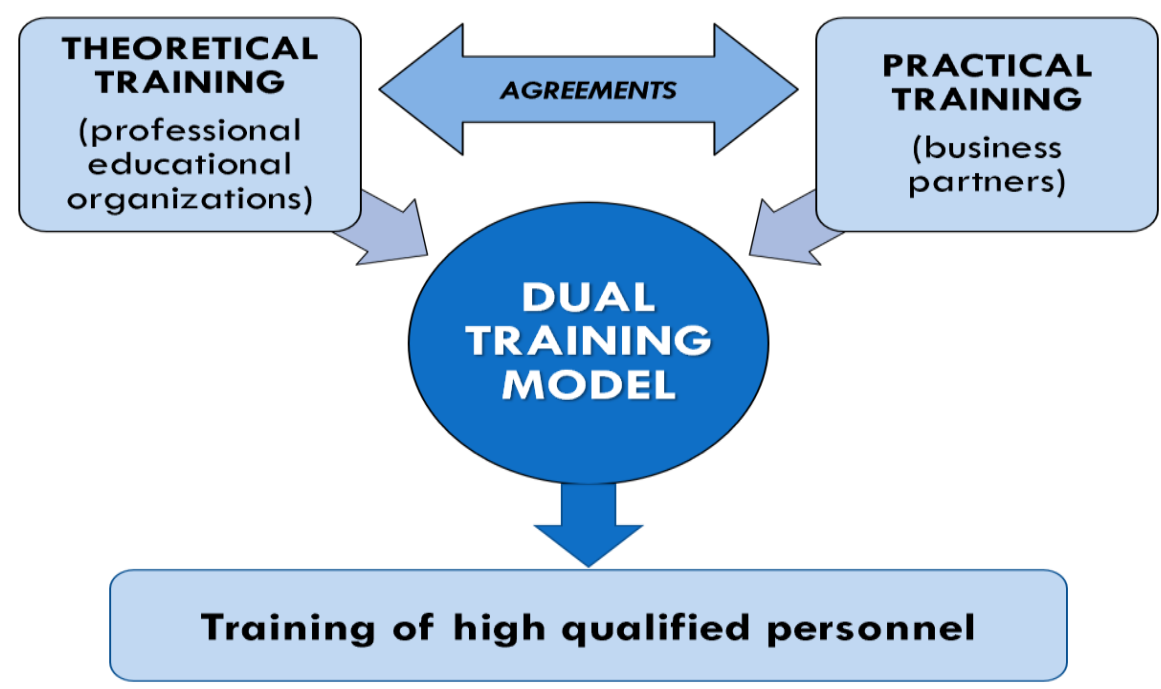

Fig. 2. Dual training model.

The countries of Western Europe (Germany, Austria, Denmark, the Netherlands, and Switzerland) have gained extensive experience in organizing dual education, as this effective form has been used for more than 50 years there. The prototype of dual training was the shop organization of labor used for teaching various crafts for centuries. As contrasted to explanatory and illustrative technology used in the old days, modern vocational education employs a lot of innovative training techniques (project-based, problem-oriented learning, modern digital technologies, etc.).

In Russia, practical training also features its own rich traditions: in the past centuries, craft training was used, and at the end of the $1880 \mathrm{~s}$, the active development of industry, agriculture, transport caused the establishing of a system of vocational education. The first vocational educational institutions were opened for training workers and foremen, assistant engineers. In the early 20th century, the project method was first successfully applied; however, it was subjected to unfounded criticism soon and "forgotten" for several decades.

In the post-war years, various measures were taken in the Soviet Union to increase the effectiveness of practical training, since both scientists and practicing teachers realized its importance for the formation of a qualified specialist. The system of mentoring was widely used in production, industrial enterprises took patronage over educational organizations, the state supported young specialists by finding jobs, providing them with housing, etc. This is a kind of positive experience that should be reconsidered and adapted to modern conditions.

The experience of organizing dual education has been actively discussed for two decades in domestic vocational pedagogy and ideas have been offered about transferring the experience of Germany to Russian conditions. But in fact, dual education in Russia is, unfortunately, underdeveloped as a system, although its positive aspects are quite explicit and understandable to everyone.

Successful establishing of the dual education system in Russia requires a well-thoughtout state educational policy aimed at developing clear market mechanisms for regulating the interaction of educational organizations and industrial enterprises-employers. All stakeholders of the study process should realize the advantages of dual education as a mutually beneficial process, as an investment in the future. For educational organizations, this is a high quality of graduate training and, as a result, the prestige and strong appeal of the organization among applicants, its status in the professional and pedagogical community. For partner enterprises, these are professional personnel trained for specific production 
conditions, adapted to professional activities and introduced to the organizational corporate culture.

\section{Discussion}

The development of network interaction between educational organizations and partner enterprises can be considered an important step in the further establishing of the system of dual education in our country. We conducted a SWOT analysis of the implementation of practical training using network technologies using the case of "Polytechnic College No. 8 named after the Twice Hero of the Soviet Union I. F. Pavlov" (PC No. 8, Moscow) and identified its strengths and weaknesses, assessed the opportunities and threats.

Strengths:

Wide application of modern teaching technologies in the study process;

Spending a large amount of time at the partner enterprise, students get more motivated to learning;

Students gain practical experience while performing gradually complicated production tasks;

Students and their parents are more satisfied with the study process due to confidence in employment, even before graduation;

Uniquely designed training programs that take into account the needs and characteristics of the enterprise;

Students can apply previously obtained theoretical knowledge in practice;

Students gain work experience recorded in their employment history book, which is a comparative advantage for graduates;

Industrial and research staff of industry enterprises, scientific organizations, and business is involved in teaching;

Teaching staff members are offered internships at modern enterprises;

Using modern equipment for advanced training of teaching staff;

Material and technical base of the college is checked for compliance with modern production requirements.

Weaknesses:

Partner enterprises have to be convinced of the benefits of network cooperation and providing effective market mechanisms for dual learning;

Monitoring the attendance and progress of students during their practical training at partner enterprises is rather difficult;

Prospective consumers are poorly aware of educational services and benefits;

The college staff needs continuous professional development.

\section{Opportunities:}

Use of modern equipment leads to the increased prestige of teaching in the system of secondary vocational education and, as a consequence, the quality of teaching staff increases;

A cohesive and efficient teaching team can be built due to the insignificant staff turnover;

The number of college applicants markedly increases;

Qualified graduates are prepared for work, taking into account the specific features of partner enterprises;

The quality of the study process increases, which, in turn, leads to an increase in the competitiveness of graduates;

The range of training areas covered by the educational organization can be revised to include more demanded and promising areas;

High level of integration of the regional industrial sector with the educational organization;

Educational organization can be confident in the employment of its graduates; 
The contribution of partner enterprises to the training of their future employees can be significantly increases.

Threats:

Possible changes in the needs of the enterprise for qualified personnel may be caused by the reorientation of production;

The need for constant updating of study equipment is usually associated with additional financial costs;

Rapid obsolescence of the material and technical facilities, library collection, and computer equipment;

The economic crisis may have direct and indirect impact on enterprises resulting is their possible closing down and consequent loss of partners for the college;

When teachers take advanced training courses, great emphasis is placed on replenishing the subject-oriented content and methodological provisions of the teacher's activities.

To assess the effectiveness of practical training, various diagnostic tools are used [17], and the list of methods employed is expanding following the digital transformation of education. The use of digital technologies in the study process opens up new opportunities for both students and teachers: learning at any convenient time and at a comfortable pace, wider opportunities for continuing education, the development of soft skills associated with the skills of analytical, critical and creative thinking, the use of digital technologies, effective teamwork and online communication, etc.

In the study process, students of PC No. 8 actively master the manufacturing of parts on metal-cutting machines of various types, including metal-working machines with computer numerical control (CNC) from DMG MORI. One of the main tasks of training specialists to operate $\mathrm{CNC}$ machines is to teach them the basics of programming. Each control system has its own characteristics, both in control and in programming. Therefore, SIEMENS has created its own training program SinuTrain, which can fully simulate the operation of its CNC models on a personal computer. SinuTrain is a software solution for high-quality and fast training of operators, adjusters and technologists-programmers in the operation and programming of SINUMERIK CNC systems. With SinuTrain, you can teach not only programming in DIN 66025, but also the ShopTurn / ShopMill software. The SIEMENS training software simulates the operation of such CNC systems as SINUMERIK 810D, 840D, $840 \mathrm{D} \mathrm{sl}, 840 \mathrm{Di}$ sl. The software runs on an ordinary personal computer with the Windows XP SP3 operating system.

SinuTrain simulates the entire technological process according to the program, which allows the teacher to check the correct operation of the program for machining parts. The virtual manufacturing of a part allows getting its exact image on a computer even before the start of manufacturing, which is very effective for practicing educational tasks.

Students can advantageously eliminate possible disruptions in the production chain. In addition to the ability to quickly eliminate errors, working in SinuTrain is cost-effective, since there is no need to use consumables and machinery equipment stock for initial practicing programming skills.

Using computer models in the process of practical training helps strengthening interdisciplinary links, developing the creative abilities of college students, forming information-handling culture and, in general, improving the quality of the development of professional competences [18]. In the context of the digital transformation of education, an important trend is the use of VR/AR technologies in the study process [19, 20], including practical training. It is important to consider these technologies not as an alternative to the real production process, but as an effective means of developing students' primary practical skills and abilities, their involvement in professional activities through immersion.

Demonstration exams according to WorldSkills standards, organized for the most objective assessment of the development of professional competences, have recently been 
considered the main tool for assessing the effectiveness of the practical training of college students [21].

In the period between February and March, 2021, students of the pre-graduation courses at PC No.8, took demonstration exams according to WorldSkills Russia standards in the Additive Manufacturing competence, as part of intermediate assessment (Code 1.1). All students successfully completed the assignments: $44 \%$ of students - with the "excellent" mark (in terms of the points of the demonstration exam for the traditional assessment system), $30 \%$ - with the "good" mark; $26 \%$ - with the "satisfactory mark". The students were assigned the task of making a project suitable for further production based on existing faulty parts. During the demonstration exam, the students demonstrated the skills of non-contact volumetric digitization (3D scanners), used specialized software and computer-aided design (CAD) systems. Given the fact that the demonstration exam for this competence was held in college for the first time, the results obtained were accepted as the results of the ascertaining stage of the experiment. In the future, the study will be continued: at the formative stage, it is planned to comprehensively implement the principles of dual education for organizing practical training in the context of the digital transformation of education.

If we compare the results of college students with those obtained on the all-Russian scale, the average score of students of PC No. 8 is 4.62 points higher than the average for Russia (see Fig. 1).

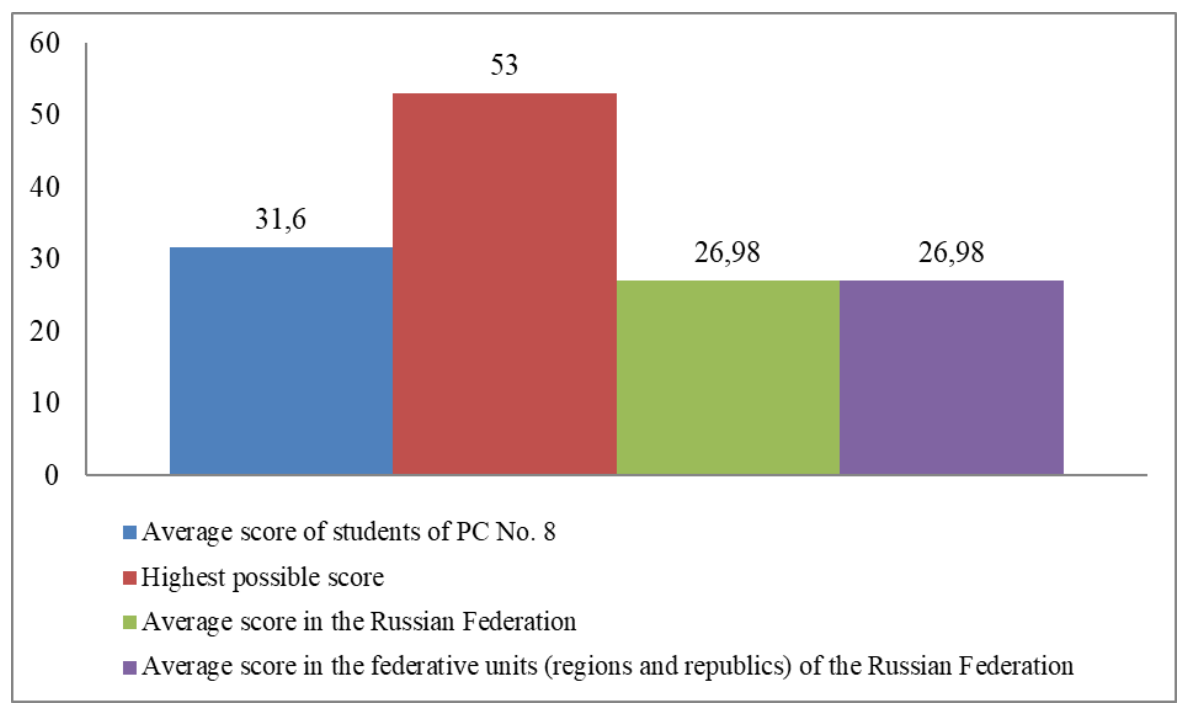

Fig. 3. Comparative characteristics of the demonstration exam results shown by students of PC No. 8 .

This can be explained by the well-organized joint work of the college and a partner enterprise for preparing students for a demonstration exam, as well as a well-structured study process with balanced theoretical and practical training. The high results of the demonstration exam indicate that college students meet the modern requirements for specialists in their field.

The intermediate demonstration exam allowed:

- expanding partnership between educational organizations by inviting third-party experts;

- objectively assessing the content and quality of training, which is extremely important in the distance learning conditions;

- identifying weaknesses in the practical training of students and outline the trajectory for the further development of its apical and implicit components in the context of the digital transformation of education. 


\section{Conclusion}

To sum it all up, the analysis of the current state of the organization of practical training in colleges shows a tendency towards the development of network interaction between educational organizations and partner enterprises. This may further lead to the establishing of a dual education system in Russia based on a network of educational and production clusters. Practical training is a key basic constituent of the content of secondary vocational education, represented by both apical and implicit components. Both components of practical training require further modernization in the context of the digital transformation of vocational education.

\section{References}

1. R. Scherer, S.K. Howard, J. Tondeur, F. Siddiq, Computers in Human Behavior 118, 106675 (2020) doi.org/10.1016/j.chb.2020.106675.

2. N. Iivari, S. Sharma, L. Ventä-Olkkonen, International Journal of Information Management 55, 102183 (2020) doi.org/10.1016/j.ijinfomgt.2020.102183.

3. M. Bratti, M. Conti, G. Sulis, Labour Economics 69, 101972 (2021) doi.org/10.1016/j.labeco.2021.101972.

4. H. Van den Berg, Learning and Individual Differences 40, 84-89 (2015) doi.org/10.1016/j.lindif.2015.04.013.

5. N.V. Kamenez, Z.V. Smirnova, O.I. Vaganova, N.V. Bystrova, J.M. Tsarapkina, International Journal of Mechanical Engineering and Technology 10(2), 899-907 (2019)

6. L. Kucirkova, A.Yu. Alipichev, D.G. Vasbieva, O.A. Kalugina, XLinguae 10(2), 63-77 (2017) doi: 10.18355/XL.2017.10.02.06.

7. S. Zain, Future Directions in Digital Information. 223-234 (2020)

8. P.F. Kubrushko, A.Y. Alipichev, E.N. Kozlenkova, L.I. Nazarova, A.S. Siman, Journal of Physics: Conference Series 1691(1), 012116 (2020). doi: 10.1088/17426596/1691/1/012116.

9. E. Fleaca, R.D. Stanciu, Procedia Manufacturing 32, 1051-1057 (2019). doi.org/10.1016/j.promfg.2019.02.320.

10. I. Ivanov, J.C. Cobo, M. Kosonogova, Procedia Computer Science 172, 517-522 (2020)

11. L. Moldovan, Procedia Manufacturing 46, 263-270 (2020). doi.org/10.1016/j.promfg.2020.03.039.

12. E.F. Zeer, V.S. Tretyakova, T.D. Bukovey, E.Y. Scherbina, Humanities and Social Sciences Reviews 7(4), 1080-1085 (2019). doi: 10.18510/hssr.2019.74147.

13. E.F. Zeer, M.V. Zinnatova, T.D. Bukovei, ARPN Journal of Engineering and Applied Sciences 12(11), 9137 (2017). doi: 10.3923/jeasci.2017.9137.9143.

14. L.V. Zanfirova, T.P. Kovalenok, E.A. Ovsyannikova, Y.S. Chistova, N.A. Sergeeva, Journal of Physics: Conference Series 1691(1), 012222 (2020). doi: 10.1088/17426596/1691/1/012222.

15. P. Kubrushko, E. Kozlenkova, O. Mikhailenko, L. Nazarova, Facilitation of Innovative Pedagogical Activity of University Teachers. Advances in Social Science, Education and Humanities Research, International Conference on the Theory and Practice of Personality Formation in Modern Society (ICTPPFMS-18) 198, 266-269 (2018) doi.org/10.2991/ictppfms-18.2018.47. 
16. P.D. Koudahl, Procedia - Social and Behavioral Sciences 9, 1900-1905 (2010). doi.org/10.1016/j.sbspro.2010.12.421.

17. E.D. Kolegova, O.B. Akimova, E.M. Dorozhkin, A.A. Malygin, N.V. Chekaleva, Astra Salvensis 6, 288-313 (2018).

18. Y. Takeichi, K. Yajima, Sh. Matsuhashi, K. Misono, Sh. Suzuki, J. Sato, Ya. Kato, Procedia Computer Science 60, 1240-1246 (2015).

19. P. Karagiannis, Th. Togias, G. Michalos, S. Makris, Procedia CIRP 96, 290-294 (2021). doi.org/10.1016/j.procir.2021.01.089.

20. K. Li, Sh. Wang, Microprocessors and Microsystems 83, 103989 (2021). doi: 10.1016/j.micpro.2021.103989.

21. L.L. Chumakov, V.E. Epishkin, IOP Conference Series: Metrological Support of Innovative Technologies 22015 (2020). doi: 10.1088/1742-6596/1515/2/022015. 